\title{
Marketing sensorial no varejo: estudo de caso da Starbucks e sua influência no nicho de cafeterias ${ }^{1}$
}

Rafaela Monnerat Martins de Andrade e Silva

Pontifícia Universidade Católica do Rio de Janeiro - PUC-Rio

Departamento de Comunicação Social - Bacharelado em Publicidade

\section{RESUMO}

Este artigo estuda uma vertente do marketing que prioriza o estímulo dos sentidos humanos chamada de marketing sensorial. Esse tipo de marketing tem como objetivo mexer, beneficamente, com a emoção dos consumidores para a marca e suas ações serem lembradas como uma experiência além de apenas uma visita ao ponto de venda ou compra de um produto.

\section{PALAVRAS-CHAVE}

Marketing sensorial; Sentidos; Experiência; Cérebro; Cafeterias.

Essa pesquisa pretende estudar o marketing sensorial aplicado em estratégias da cafeteria Starbucks. Essa vertente do marketing se preocupa com as sensações e impressões que o ponto de venda, as propagandas e o produto, por exemplo, causam, tentando manter a marca fixada - como algo positivo - na mente do consumidor.

O marketing, de uma forma geral, se baseia em um processo de troca entre quem vende e quem compra, no qual o objetivo é a satisfação do consumidor. Diferentemente do departamento de vendas, que procura vender um produto já pronto, o marketing idealiza o que o cliente necessita para oferecer a ele em seguida. Às vezes o próprio consumidor sabe o que quer, mas não o que precisa. O papel do departamento de marketing é antecipar essa necessidade.

Ao longo do tempo o marketing passou a ser percebido como uma área de atuação no mercado diferente das vendas. Ele passou a penetrar em toda a empresa e integrar cada processo de produção daquele produto, serviço ou qualquer outro item a ser comercializado (SHIMOYAMA e ZELA, 2002).

\footnotetext{
1 Artigo derivado de monografia de graduação em Publicidade, orientada pela professora Bárbara Assumpção e apresentada em dezembro de 2019.
} 
A partir disso, novas estratégias foram surgindo. A estratégia dos 4 P's, que significam Produto, Preço, Praça e Promoção, também chamada de marketing mix, visa equilibrar esses quatro elementos para atingir o sucesso de lançamento de produtos, serviços e valores. Esse formato, visto como ideal, já é obsoleto. Agora, ao invés de quatro, são 8 P's. A inclusão de mais P's mostrou que existem processos que vão além das etapas de produção do produto e a chegada dele aos pontos de venda. Não basta chegar à loja, por exemplo, tem que se atingir o público alvo e ser comprado por ele. Agora, então, Pessoas, Processos, Posicionamento e Performance também passam a ser itens chave na hora de montar um plano de marketing completo e integrado (GABRIEL, 2019).

Percebe-se que o processo de compra e venda mudou e o marketing também. Os novos P's já deixaram de ser, majoritariamente, tangíveis e passaram a significar que muito do que está em jogo na hora de cativar o consumidor é intangível. Satisfazer uma necessidade vai além do que se está comprando (GABRIEL, 2019). Antes de conquistar um consumidor com o objetivo de torná-lo cliente, a marca precisa ser lembrada para se destacar entre as demais. Daí surge um marketing diferente do que se baseia em quatro ou oito P's, o marketing sensorial.

O marketing sensorial está longe de ser majoritariamente racional e técnico. Ele é uma das vertentes do marketing e, como o nome sugere, mexe com os cinco sentidos - visão, audição, olfato, paladar e tato.

Esses, que são os objetos centrais de estímulo do marketing sensorial, correspondem às percepções de mundo do ser humano e estão diretamente ligados à memória e recordações (SANTOS et al., 2016).

Os sentidos são estimulados pela percepção sensorial do corpo. Como essa percepção faz associações neurais, resgatam lembranças e trazem consigo emoções. Essa técnica tem o potencial de trazer à memória do consumidor um momento especial da sua vida num instante. (OLIVEIRA e BRAGA, 2013, p.4)

O modelo de pensamento proposto pelo psicólogo Daniel Kahneman divide o cérebro em dois Sistemas, 1 e o 2. 01 é o Sistema que sempre foi usado para garantir a manutenção da vida e da espécie, que cuida do que é automático, não precisa ser pensado para que haja reação. 02 é o lado que é responsável pelo o que é mecânico, ou seja, precisa do raciocínio e pensamento. O Sistema 1 é emocional e o 2, racional. O sensorial tem associação neural com o Sistema 1 do cérebro gerando memórias 
emocionais, indispensáveis em momentos de tomadas de decisão (DAMÁSIO, 1994; KAHNEMAN, 2011).

De acordo com Ariano², as emoções determinam nossas escolhas e, quando uma marca é gravada como algo positivo na memória do cliente, é mais fácil que ela seja escolhida durante o processo de tomada de decisão. Em conflito, o um sempre vence o dois. Segundo Damásio (1994), a emoção, fator determinante para as escolhas, é tudo o que o ambiente - incluindo pessoas - pode causar num organismo que dispare uma ação, seja ela consciente ou não. Emoções são automáticas e incontroláveis, uma resposta neural para estímulos externos.

Na obra O Erro de Descartes, o autor contrapõe a ideia de que as tomadas de decisão são melhor concluídas quando a emoção está distante da razão. Ele observa que em situações patológicas, quando o paciente tem alguma deficiência relativa aos impulsos emocionais, a razão se mostra de forma falha. A hipótese do marcador somático, apresentada por ele, inclui a emoção ao processo de raciocínio como um auxiliar à razão, e não um dificultador, como suposto normalmente (DAMÁSIO, 1994).

É evidente que a vertente convencional e racional do marketing, o dos P's citado anteriormente, é importante e não deve ser deixada de lado, afinal, quando o Sistema 1 encontra algum tipo de dificuldade, recorre ao 2 para que haja uma manipulação mais detalhada da situação e solucione o problema (KAHNEMAN, 2011).

Pular para as conclusões é arriscado quando a situação é pouco familiar, existe muita coisa em jogo e não há tempo para reunir mais informação. Essas são as circunstâncias em que erros intuitivos são prováveis, os quais podem ser evitados com uma intervenção deliberada do Sistema 2. (KAHNEMAN, 2011, n.p.)

O Sistema 1 do cérebro foi projetado para avaliar e responder a qualquer tipo de ameaça, desde sempre, mesmo que elas sejam simbólicas e, às vezes, não representem um perigo de fato. Palavras negativas têm mais destaque na mente humana do que as positivas:

O marketing sensorial, inclusive, deve ser usado com cautela. Kahneman explica que, dependendo de como a situação é

${ }^{2}$ Informação fornecida por Érica Ariano no curso Marketing Sensorial: Porque a experiência é a parte mais importante da venda, em São Paulo, em abril de 2019. 
mostrada ou narrada, até palavras negativas captadas pelo cérebro são percebidas como ameaça quando, na verdade, não existe perigo algum: "seus pensamentos e comportamento podem ser influenciados por estímulos nos quais você não presta a menor atenção, e mesmo por estímulos dos quais não tem a menor consciência." (KAHNEMAN, 2011, n.p.)

Quando o ser humano tira conclusões sobre gostar ou não de coisas e pessoas, é movido pela emoção e afeto. Se alguém se mostra como uma pessoa responsável e atraente, por exemplo, é mais fácil que o cérebro associe coisas boas a ela ao invés de coisas ruins, mesmo que não saiba mais nada sobre a vida daquele indivíduo. Isso se dá pelo efeito halo: "A tendência a gostar (ou desgostar) de tudo que diz respeito a uma pessoa - incluindo coisas que você não observou" (KAHNEMAN, 2011, n.p.).

O efeito halo não se relaciona somente com pessoas, o ambiente também deixa suas impressões nos Sistemas humanos através de diferentes meios:

estimulação da atividade neural dos olhos [...], dos ouvidos [...], e das miríades de terminações nervosas localizadas na pele, nas papilas gustativas e na mucosa nasal. As terminações nervosas enviam sinais para pontos de entrada circunscritos no cérebro, os chamados córtices sensoriais iniciais da visão, da audição, das sensações somáticas, do paladar e do olfato. (DAMÁSIO, 1994, n.p.)

A partir disso nasce o conceito de priming: "[...] nossos pensamentos e nosso comportamento são influenciados, muito mais do que sabemos ou queremos, pelo ambiente do momento" (KAHNEMAN, 2011, n.p.). Esse efeito é bastante explorado em pontos de venda de marcas que trabalham a área de experiência do consumidor através dos cinco sentidos. Patrícia Holanda observa o uso do priming no marketing sensorial: "[...] o marketing experiencial ou sensorial explora os estímulos ambientais captados por essas diferentes fontes, baseando-se nos fundamentos fornecidos pela percepção, ao se descrever a impressão canalizada por cada" (HOLANDA, 2005, p.25). Se o ambiente ou ação publicitária que está sendo colocada em prática emitir algum estímulo negativo, todas as lembranças, relativas à aquela marca ou lugar, que os consumidores resgatarem serão negativas (HOLANDA, 2005).

Todos os sentidos são importantes e atuam em conjunto para alcançar um único objetivo - conectar os seres vivos ao meio em que vivem -, mas o olfato se mostra um pouco diferente dos demais porque "as sensaç̃oes que surgem da excitação do nariz podem assumir uma qualidade de prazer ou repúdio únicos" (HOLANDA, 2005, 
p.36). Os estímulos relacionados aos quatro demais sentidos humanos podem ser ignorados mais facilmente do que os odores (HOLANDA, 2005).

O olfato também é um sentido que é responsável por captar informações - além do mundo externo - do próprio corpo, de dentro da boca. O sabor, notado pelo paladar, é percebido, em grande parte, pelo olfato. Assim como o cérebro associa cheiros à alimentos, pode associar a outras coisas como marcas, por exemplo (HOLANDA, 2005).

A visão é o sentido mais explorado. O odor, por exemplo, apesar de ser muito importante, não é tão usado como ferramenta do marketing sensorial. Ele é classificado como o segundo sentido mais importante, com $45 \%$ de relevância para os consumidores, e somente $1,9 \%$ da verba das companhias é destinada a aguçá-lo (LINDSTROM, 2005).

O olfato e o paladar, porém, são sentidos muito explorados em cafeterias - enquanto, normalmente, a visão e a audição são o foco da maioria das experiências sensoriais do varejo.

\begin{abstract}
Pesquisas feitas com base na utilização dos cinco sentidos mostram que o visual é o mais explorado, assim como a audição. Isso demonstra o quanto é necessário que os profissionais de marketing descubram a abordagem dos outros três sentidos, capazes de resgatar memórias e despertar emoção no receptor, proporcionando em muitos casos a inclusão social, que é deixada de lado no formato tradicional. (OLIVEIRA e BRAGA, 2013, p.2)
\end{abstract}

Dessa forma, esse artigo irá explorar a maneira de fazer marketing da Starbucks que hoje, com mais de 15 mil lojas em 50 países, é a mais importante empresa mundial de torrefação e venda de café especial, de acordo com a própria multinacional. (STARBUCKS Corporation, 2019). Antes mesmo do marketing sensorial se tornar uma nova chancela conhecida do marketing, a cafeteria americana já adotava o discurso de colocar a vivência do consumidor - relacionada à marca - acima de tudo.

A Starbucks não tem campanha de mídia de massa aqui e em nenhum lugar. A estratégia de marketing é in-store. Significa que nossas campanhas são produzidas e divulgadas nas nossas lojas. Não existe filme para TV, campanha de jornal, revista e outdoor. A Starbucks é intimista e a experiência se dá dentro da loja. Não adianta tentar reproduzir isso de forma impressa porque o consumidor deixará de ser tocado em alguns dos nossos pontos. Mesmo que tenha um filme, o 
consumidor não terá um contato pessoal com um Partner. Tudo é voltado para dentro da loja. (MAESO, 2009, online)

A marca teve sua primeira loja inaugurada em Seattle, 1971, já com a proposta de "ser um tipo de empresa diferente, que não apenas celebrava o café e sua rica tradição, mas também trazia um sentimento de conexão" (STARBUCKS Corporation, 2019, online). A missão da empresa é "inspirar e nutrir o espírito humano - uma pessoa, uma xícara de café e uma comunidade de cada vez" (STARBUCKS Corporation, 2019, online).

A Starbucks valoriza relações interpessoais tanto com os clientes, quanto com os produtores do café. Dentre as etapas de plantio e colheita dos frutos, a marca frisa o "cultivo de relacionamentos". Ajudar os produtores a conseguirem melhores resultados, na visão da marca, é um fator que precisa beneficiar a todos inclusos no processo de cultivo dos grãos.

\begin{abstract}
Para isso, temos centros de apoio aos produtores nos quatro continentes onde nossos agrônomos testam solos, examinam amostras e oferecem aconselhamento gratuito, para os nossos produtores de café. O futuro do café está entrelaçado com o futuro dos produtores de café. Então, cultivamos estes relacionamentos da mesma forma que eles cultivam seus grãos. Trabalhamos para proporcionar aos produtores um preço justo e para ter certeza que todos na comunidade possam se beneficiar da indústria do café. Isto conduz a um melhor meio de vida para os produtores, e uma melhor xícara de café para todos nós. (STARBUCKS Corporation, 2019, online)
\end{abstract}

A cafeteria criou uma comunidade chamada Starbuck Shared Planet que declara "compromisso de fazer negócios de uma forma que seja benéfica para as pessoas e o planeta" (STARBUCKS Corporation, 2019, online). Através dela, a marca promete a redução de impacto ambiental, luta contra mudanças climáticas e tem maior envolvimento com a comunidade que a cerca, dando preferência ao uso de material e mão de obra local na construção e reforma de suas lojas, por exemplo.

A presidência da marca, recentemente, mudou de responsável. Em 2018, Kevin Johnson assumiu a liderança e mudou o foco da estratégia de mercado da Starbucks Corporation. Ele declarou que 150 unidades da empresa - com performance precária - seriam fechadas e que a marca deveria agir de forma que atendesse as expectativas e necessidades dos clientes (SALOMÃO, 2018). 
A marca tem uma visão global, como a empresa internacional que é, mas olha para suas filiais como parte da comunidade onde se instalam. De acordo com isso, se adequa aos países e regiões onde está presente. Essa adaptação é visível nas variações de itens dos cardápios, por exemplo.

O cardápio é basicamente o mesmo, mas com adaptações a cada lugar. Nos Estados Unidos o cliente pode escolher um Frappuccino sabor S'mores - sobremesa típica -, cidra de maçã aquecida, e Refreshers de açaí, uma exclusividade do cardápio norte americano, por mais que a fruta seja nativa da região amazônica. Na Europa, o enfoque do cardápio são os chás de sabores indisponíveis em outras regiões. No Brasil, há itens quentes e gelados sabor brigadeiro, doce de leite e Frappuccino de açaí. O cardápio de lanches e refeições também varia de acordo com a localização da cafeteria.

Essas variações presentes em cada menu podem ser consideradas parte do marketing de experiência, marca registrada da loja. Incluir comidas típicas, além de agradar os nativos, se torna um atrativo para visitantes imergirem na cultura local mesmo estando na sua zona de conforto. A Starbucks representa um ambiente familiar para os clientes. Não importa em que parte do mundo eles estejam, basta avistar uma cafeteria da marca para identificá-la como um lugar habitual, parte do cotidiano.

Além do cardápio permanente de cada país, a Starbucks apresenta itens referentes a datas especiais ou edições limitadas. Aqui no Brasil, por exemplo, em agosto de 2018, foi lançado um dos Frappuccinos mais icônicos da cafeteria, o Galaxy Frappuccino, bebida que propõe uma nova experiência a cada gole: feita de glitter, cores que lembram a galáxia e aroma de algodão doce combinado com uva, os sabores e cores se transformam a cada gole. Sandra Collier, gerente sênior de marketing da Starbucks Brasil, em entrevista veiculada pelo Guia do Profissional de Hotelaria e Restaurantes, associa a inovação à experiência Starbucks:

A inovação é um pilar constante da Experiência Starbucks ${ }^{\circledR}$, sempre orientado para enriquecer os momentos de cada um dos nossos consumidores. Essa bebida foi criada aqui no Brasil e estará disponível em alguns mercados da América Latina. O Galaxy Frappuccino ${ }^{\circledR}$ nasceu após meses de estudo e levantamento de tendências, a fim de oferecer uma bebida diferenciada que pudesse elevar essa experiência [...] Dentro do cardápio customizável da Starbucks $®$, o Frappuccino $®$ é uma das opções mais divertidas da marca em todo o mundo, sempre ganhando novas composições e temas 
comemorativos. Estamos felizes por trazer aos fãs da

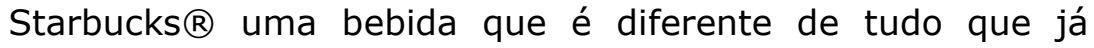
criamos. (COLLIER, 2018, online)

Em maio de 2019, enquanto a última temporada da série Game of Thrones, produzida pela HBO, era veiculada, apareceu, durante um episódio, um copo de café da Starbucks apoiado na mesa em frente onde Daenerys Targaryen estava sentada. (MEIO E MENSAGEM, 2019). Os poucos segundos de aparição - extremamente sutil - do copo da marca foram suficientes para que a internet ficasse cheia de memes e questionamentos para saber se era, de fato, uma propaganda ou apenas um erro cenográfico.

Dois dias depois do ocorrido, a Starbucks lançou uma bebida chamada Dragon Drink, traduzida como Bebida do Dragão. O lançamento da bebida gelada à base de dragon fruit, a fruta conhecida pelos brasileiros como pitaya; manga; leite de coco e gelo, foi uma alusão à Daenerys, Mãe dos Dragões, na série GOT. O produtor executivo de Game of Thrones, Bernie Caulfield, então, admitiu ser um erro da produção, e não publicidade (MEIO E MENSAGEM, 2019).

A cafeteria, entretanto, já tinha aproveitado o momento para "entrar na brincadeira", ganhar visibilidade e vender muitos Dragon Drinks. A CEO da Hollywood Branded uma agência de marketing de entretenimento -, Stancy Jones, revela que, de acordo com seus cálculos, a Starbucks gerou US\$ 2,3 bilhões de dólares em marketing espontâneo apenas nos primeiros dias da semana em que foi lançado o episódio (CORAL, 2019).

Isso é experiência do consumidor: aproveitar uma oportunidade de segundos e fazer fãs da série se engajarem, irem até a loja, provarem a novidade referente ao programa de televisão que amam e compartilharem nas mídias sociais. O principal é a experiência de provar a bebida da Mãe dos Dragões. Matar a sede é um bônus.

Os pontos de venda da cafeteria também são bastante característicos e padronizados. Ao entrar na cafeteria, percebe-se, logo, o aroma de café torrado, a luz mais baixa, aconchegante, tons amadeirados e em cobre, sofás compostos por mesinhas baixas, cadeiras acolchoadas, mesas altas espalhadas, muitas tomadas à disposição e Wi-Fi grátis. As lojas da Starbucks são espaços de convivência. O ambiente é projetado para atender todo tipo de cliente com a combinação do 
aconchego e acolhimento de suas casas e a rapidez de um fast-food. Chamar os clientes pelo nome também gera um vínculo afetivo e identificação com a marca.

Além dos tradicionais pontos de venda da empresa, recentemente ela vem lançando outras variações das lojas, como a Starbucks Reserve $($ Roastery, um espaço enorme e sofisticado da Starbucks que pode ser classificado como um museu cafeeiro. A Roastery está presente em cinco localidades do mundo e cada uma delas conta com vários bares; restaurantes; áreas de torra e produção do café; visita guiada e bastante tecnologia para aprimorar a experiência. A própria marca as define como espaços de imersão que convidam os clientes a descobrir e explorar os mais raros e extraordinários cafés que a Starbucks tem a oferecer (STARBUCKS Reserve, 2019).

A loja é uma grande experiência surpreendente e multisensorial. A Starbucks frisa que todas as áreas da loja são interativas, pensadas no uso dos clientes. Após as experiências gustativas entre os quatro bares, considerados obras primas pela marca e descritos como voos e experiências, o Bar Principal, o Bar da Experiência, o Scooping Bar e o Arriviamo ${ }^{\mathrm{TM} B a r}$, os clientes são convidados a ir até área de torra, que é onde os cafés são torrados perfeitamente, com a precisão de tempo e calor ideais, garantindo que se destaque o melhor de cada grão de café.

Deixando a experiência ainda mais completa, a Starbucks disponibiliza, em inglês, na App Store, um aplicativo grátis complementar à visita. O App Starbucks Reserve ${ }^{\circledR}$ Roastery New York possibilita ao usuário entrar ainda mais no universo do café que irá experimentar no tour da loja. O primeiro passo é plantar uma árvore de café virtual - que cresce em realidade aumentada - para que depois, o consumidor possa mergulhar a fundo nas técnicas e conhecer a arte e ciência necessárias para o cultivo, torra e apreciação do café. No final da visita, é possível aprender como preparar um dos mais extraordinários cafés que a Starbucks tem para oferecer.

No espaço inaugurado pela Starbucks, os consumidores são envolvidos em situações emocionais durante toda a visita. Experimentar os cafés, chás, coquetéis e aperitivos é mais importante do que saber do quanto o consumidor deve pagar por cada item consumido. O Marketing Sensorial é sobre priorizar as experiências do cliente ao longo de todo o momento de tomada de decisão ao invés de privilegiar a razão, pura e exclusiva, sobre o desejo do consumidor de beber café expresso ou não. 
[...] o marketing experiencial ou sensorial explora os estímulos ambientais captados por essas diferentes fontes, baseando-se nos fundamentos fornecidos pela percepção, ao se descrever a impressão canalizada por cada. (HOLANDA, 2005, p.25)

Atividades como plantar uma árvore virtual no aplicativo mexem com múltiplos sentidos do organismo humano, com tato, visão e gera laços emocionais a partir do momento em que a semente é plantada pelo cliente e ele assiste o desenvolvimento do que plantou.

Na loja, o cheiro do café moído - na área da torra - vai direto ao encontro do nariz do cliente, que dificilmente pode se esquivar do odor, altamente potente em trazer recordações. O olfato é o sentido que mais tem impacto emocional. Quando algum cheiro é associado a um produto, ao senti-lo, a pessoa é induzida a consumir tal item.

Logo depois, o consumidor é surpreendido com diferentes estímulos gustativos, ao visitar os quatro bares da loja. O que já foi experimentado pelo olfato, passa para o paladar. A possibilidade de aprender sobre os diferentes utensílios capazes de influenciar o sabor da bebida - escolher com qual desses quer que o seu café seja preparado - e poder, depois, comprá-los para preparar, com suas próprias mãos, o café em casa, também é uma $A$ ajuda dos baristas - a todo tempo - também faz parte do ambiente sensorial:

[...] pesquisas consideram como fatores de influencia toda a atmosfera ambiental, desde fatores sociais, que se referem à qualidade do atendimento, incluindo aí a maneira como os funcionários estão vestidos, sua educação e cortesia, até os aspectos funcionais e estéticos do ponto de venda, como estilo, cor, decoração, temperatura, layout, conforto, iluminação e som. (HOLANDA, 2005, p.73)

O design da loja, composto de madeira escura, cobre, e iluminação modesta, é bem aconchegante e clássico. O teto é composto de quadrados e retângulos, inspirados na arquitetura da própria cidade, e canos por onde os grãos de café torrados passam fazendo um barulho de água até chegar aos bares. Além de mexer com a visão, dessa vez, a audição também entra em cena. Um espaço é destinado ao verde - um terrário de árvores e plantas inspiradas na fazenda Starbucks de Costa Rica. A natureza em meio a selva de pedra é pensada para ser sentida como uma viagem de alguns minutos. O aconchego é complementado por uma lareira (WARNICK, 2018). 
A própria designer responsável, Liz Muller, comenta que o ambiente é feito para ser um lugar parte do dia-a-dia das pessoas. Um lugar onde se encontra amigos ou visita sozinho, ideal para conhecer o amor da vida - um lugar de experiência (WARNICK, 2018).

A Starbucks Reserve ${ }^{\circledR}$ Roastery é o auge da Starbucks experience. Experiência essa que transformou o consumo de café em um estilo de vida e vem moldando cafeterias ao redor do mundo todo. A cultura de beber café antes da febre Starbucks e depois dela não é a mesma.

Marcas consolidadas no mercado internacional há anos, como a antiga Dunkin' Donuts, agora Dunkin', estão revendo toda a sua estratégia de marketing e publicidade para competir com a protagonista. A Dunkin' já era chamada assim por alguns clientes, como se fosse um apelido mais íntimo. Em 2019, o apelido virou o novo nome oficial da marca. Tirar os donuts do nome é o mesmo que avisar aos consumidores que a Dunkin' oferece mais do que rosquinhas.

De acordo com o CEO da cafeteria e presidente das unidades dos Estados Unidos, David Hoffman, essa mudança (do nome) também reitera a proposta de reposicionamento e modernização da marca tanto em questões visuais das próprias lojas - dentro e fora dos estabelecimentos -, quanto das propagandas e embalagens relacionadas à Dunkin'. Mesmo com todas as transformações, que acreditam ser positivas e convenientes para os clientes, a marca também não pretende se distanciar das origens (DUNKIN' Newsroom, 2018).

A lanchonete inaugurou recentemente uma loja em Nova York a qual eles se referem como "loja do futuro", uma experiência mais moderna e digital (TYLER, 2018). A marca começa a se ressignificar a partir do momento no qual usa a palavra mais atual do marketing, muito usada por marcas como Coca-Cola, Disney e Starbucks: experiência.

A cafeteria vai remodelar, no mínimo, mais 30 pontos de venda além do citado e testar variações em cada um deles para maiores adaptações. A Dunkin' descreve essas novas lanchonetes como inovadoras e destaca as principais novidades: caixas de atendimento $100 \%$ digitais, novos uniformes para a equipe, um sistema de 
torneiras para servir oito opções de diferentes bebidas geladas, incluindo chás e cold brews $^{3}$ e, em algumas lojas, um drive-thru exclusivo para pedidos feitos através de dispositivos móveis como smartphones e tablets (DUNKIN' Editorial Staff, 2018).

Um problema notado é que, mesmo com toda a promoção e expectativa gerada pela própria marca, as resenhas - escritas por consumidores - relacionadas às mudanças são desanimadoras. Apesar de atestarem a qualidade dos produtos Dunkin', o ambiente não gerou tanto entusiasmo. Em um artigo escrito para a Business Insider, Jessica Tyler (2018) menciona que os displays de comida e cardápio que ficam nos caixas são iguais aos antigos e a loja conta com poucas mesas e lugares para sentar. A luz ambiente é forte e nada aconchegante. A maior mudança foi o sistema de torneiras e o pouco uso das cores vibrantes do logo, rosa pink e laranja, deixando a unidade mais minimalista.

Isso demonstra que modernização nem sempre é sinônimo de experiência do consumidor. Tocar nas telas para fazer o pedido e ver a bebida saindo de uma torneira diferente pode ser legal, mas não se caracteriza como algo que necessariamente vá ser lembrado pelo cliente como especial. Não há nada mais normal para pessoas deste século do que trocar relações interpessoais por toques em telas de máquinas. Não é porque o cliente toca em uma tela touch para escolher o sabor da rosquinha que o seu sentido do tato está sendo ativado de forma correta. O diferencial do futuro não são máquinas e sim experiência (GENEZE, 2018). Esses fatores não podem ser confundidos - e nem percebidos como iguais - de forma alguma.

O costume de beber café existe há séculos, mas ele é modificado ao passar dos anos, como tudo que faz parte do mundo capitalista. As pessoas não bebem café como bebiam há 100 anos atrás.

Um dos fatores para a ocorrência de tais mudanças é a ascensão de lojas que comercializam a bebida de diferentes formas. Segundo Oliveira, o crescimento das

\footnotetext{
${ }^{3}$ Cafés gelados preparados através de infusões de nitrogênio.
} 
grandes cafeterias traz o público jovem ao ambiente que, antigamente, era ocupado por pessoas mais velhas (2018).

Se antes o café era uma bebida apreciada principalmente pelos mais velhos, hoje o crescimento de grandes cafeterias está trazendo um novo público para o consumo de cafés especiais. Atualmente as cafeterias são pontos de encontro onde os jovens se reúnem para conversar e apreciar um bom café. (OLIVEIRA, 2018)

No Brasil, por exemplo, o grão sempre foi produto de exportação e a forma mais tradicional de consumi-lo é com consistência mais forte, encorpada e sem muitas misturas, o cafezinho preto - como é chamado popularmente. As derivações começaram a surgir: café com leite, pingadinho ${ }^{4}$, cappuccino, nada muito além do tradicional. Em 2002 a onda das cafeterias americanas chegou em território brasileiro e foi se expandindo aos poucos, 31 anos depois da abertura da primeira loja Starbucks. (CALIFORNIA Coffee, 2019)

A California Coffee foi a marca que introduziu o estilo Starbucks de beber café no Brasil, eles chamam de Specialty Coffee House, uma cafeteria especial. A marca diz ser a pioneira em "bebidas geladas e quentes com e sem café [...]" no país. (CALIFORNIA Coffee, 2019)

Atualmente, muitas empresas tradicionais estão se moldando a esse estilo para continuar sendo percebidas pelo mercado. A Pilão, marca que nasceu em 1978 e é muito famosa no Brasil pelo seu pó de café, também resolveu inovar. Apesar de ser reconhecida como a "segunda maior empresa de café do mundo, com mais de 20 marcas e uma vasta experiência neste mercado" (PILÃO, 2019), de acordo com o próprio site da marca, a Pilão deu um passo a mais e, além de todas as outras linhas de produtos, criou a Casa Pilão, uma franquia de lanchonetes que "une o aconchego da casa ao charme da cafeteria" (PILÃO, 2019).

As unidades, porém, estão longe de ser apenas cafeterias. Além da marca estar sempre promovendo ações, como drinks em promoção e produtos sazonais no cardápio, para atrair público para o local, eles também lançam produtos da linha Pilão que só serão vendidos em outros PDV's posteriormente.

Fornecemos na Casa Pilão as cápsulas compatíveis com Nespresso, que lançamos em julho e somente agora

\footnotetext{
${ }^{4}$ Café misturado com pouco leite.
} 
(setembro) está chegando no varejo. Essa foi uma forma encontrada de criar um novo tipo de valor e ganhar o interesse desse consumidor que está cada vez mais exigente. (SOUZA, 2015)

Além de tudo, o discurso da Pilão em relação a essas lanchonetes é muito intimista: "A Casa Pilão é toda sua". Dizer que a casa é do cliente é o mesmo que torná-lo ativo naquele lugar, traz a mesma sensação de ser chamado pelo nome quando seu pedido fica pronto.

Outra marca que está reformulando suas lojas e criando um ambiente mais ligado a experiência do cliente é a Nespresso. Seus 27 pontos de venda espalhados pelo Brasil, sempre chamados de Boutique Nespresso, passarão por essa transformação já iniciada na loja mais antiga da marca, na Rua Oscar Freire, em São Paulo. O novo conceito adotado pela Nespresso representa um maior envolvimento com o cliente. A boutique conta com um bar que, além de oferecer coquetéis autorais, é palco para masterclasses - que acontecem o dia inteiro, todos os dias - sobre o universo cafeeiro. $O$ atendimento também mudou: para evitar que os clientes ficassem presos a filas, a lista de espera se tornou virtual, dando liberdade para o consumidor transitar por toda a loja enquanto espera (MORI, 2019).

As marcas que estão sendo criadas recentemente também inovam, cada uma a sua maneira, porém sempre trazendo o espírito da coffeehouse americana.

A CoffeeTown ${ }^{\mathrm{TM}}$ - The American Coffee and Cake, Co. é uma cafeteria brasileira que nasceu através de uma paixão hereditária por café. Luiz Santi, CEO da CoffeeTown ${ }^{\mathrm{TM}}$, é de uma família estrangeira que sempre foi ligada à produção de café. Ao longo da vida, acabou se desvencilhando dos grãos e se tornou um profissional de marketing. Depois virou consultor, depois professor universitário e depois foi para os Estados Unidos aprender mais sobre o café e reavivar sua paixão. Luiz conta que conheceu inúmeros lugares e pessoas nessa jornada que o motivaram a inaugurar a cafeteria.

A Coffeetown ${ }^{\mathrm{TM}}$ - The American Coffee and Cake, Co. [...] mais do que um lugar de vender café, tornou-se um lugar para celebrar o bom humor e o prazer de encontrar amigos, conversar e tomar os melhores cafés do mundo, além de sobremesas americanas clássicas e comfort foods saudáveis. Desde então foram abertas 22 lojas, no Rio de Janeiro, São Paulo, Vitoria, Recife e Salvador. Muitas outras ainda estão por vir. (SANTI, 2019) 
A marca se diz pioneira no mercado de cafeterias brasileiras de serviço customizado e completo com enfoque em entrega de experiências aos clientes. A cafeteria já adota o esquema de franquias e está em expansão no Brasil. Além da estética vintage super agradável e instagramável, o cardápio da CoffeeTown ${ }^{\mathrm{TM}}$ é bastante americanizado, apesar de adaptações ao paladar regional, lembrando a essência Starbucks.

Dessa forma, é possível observar que existe uma mudança acontecendo no mundo do varejo. $\mathrm{O}$ ambiente e a qualidade, origem e variedade dos produtos vendidos se tornaram mais ou tão importantes quanto o preço, por exemplo. O marketing de experiência está sendo implantado na maioria das lojas para que as marcas sejam vistas e lembradas de forma positiva pelos clientes. 2020 é o ano em que a experiência do consumidor superará o preço e o produto, em si (NEWMAN, 2018).

Entre as marcas citadas, todas tentaram adotar 0 marketing de experiência relacionado aos sentidos humanos. Algumas conseguiram conduzir essa mudança de estratégia de forma positiva, outras tiveram problemas. A Starbucks é percebida pelos clientes e pelo mercado como um bom exemplo de como colocar aplicar o uso dos sentidos ao marketing, tendo sucesso em suas ações. O caso mais problemático vem da Dunkin', no qual a mudança não foi percebida pelos consumidores mesmo com toda a ressignificação da marca. As outras lojas citadas estão implantando o marketing sensorial aos poucos, com acertos e erros, mas seguindo no caminho do sucesso.

Durante a leitura dessa pesquisa acadêmica é possível reparar que, de fato, o marketing sensorial, assim como já mencionado, é uma vertente do marketing que veio para ficar e já está fazendo a diferença. Os sentidos ajudam a fixar as marcas no cérebro das pessoas e, sabendo usá-los de forma correta, é possível arquitetar experiências incríveis, seja em pontos de venda, anúncios e ambientes on ou offline.

Admitir que a emoção é aliada da razão é imprescindível para criar estratégias menos robóticas e mais humanas. Não existe experiência sem que nenhum sentimento seja despertado e, de fato, os sentidos humanos são responsáveis por desencadear esse tipo de envolvimento entre a marca e o consumidor.

A análise mostra que a Starbucks, realmente, consegue incluir o marketing de experiência de forma eficaz tanto nas cafeterias - sendo muito bem adotado na Reserve Roastery, por exemplo - quanto nas ações da marca. 
Também se percebe, ao longo dos capítulos, que nem tudo se caracteriza como experimentação para o cliente. Ainda existe uma confusão ao classificar tecnologia de ponta como sinônimo de experiência do consumidor. Apesar de um fator não excluir o outro, máquinas, gadgets e internet são apenas facilitadores que ajudam a colocar a experiência em prática.

Hoje o marketing sensorial está sendo aplicado e mostra resultados positivos, mas como será daqui para frente? Se, em 2020, a experiência passa a ser o diferencial da marca (NEWMAN, 2018), todas as empresas, a partir de agora, adotarão o marketing voltado para os estímulos emocionais do cérebro? Como serão as experiências do futuro? Será que existe um prazo de validade para tudo isso?

\section{Referências}

CALIFORNIA Coffee. Sobre. 2019. Disponível em:

<https://www.facebook.com/pg/Californiacoffee/about/?ref=page_internal>. Acesso em: 30 de outubro de 2019.

CALIFORNIA Coffee. Visão geral. 2019. Disponível em: <https://www.linkedin.com/company/california-coffee/about/>. Acesso em: 30 de outubro de 2019.

COFFEETOWN. Sinta-se bem. 2019. Disponível em: <https://coffeetown.com.br/>. Acesso em: 10 de novembro de 2019.

COFFEETOWN Vila Mariana. Página do Facebook. 2018. Disponível em: <https://www.facebook.com/coffeetownvm/photos/amanhecer-na-coffeetown-vilamariana-vem-conhecer-a-gente-e-compartilhar-bons-mo/650253021979724/>. Acesso em: 10 de novembro de 2019.

CORAL, Guilherme. Starbucks ganhou mais de US\$ 2 bilhões em propaganda graças a Game of Thrones. 2019. Disponível em:

<https://observatoriodocinema.bol.uol.com.br/series-e-tv/2019/05/starbucksganhou- mais-de-us-2-bilhoes-em-propaganda-gracas-a-game-of-thrones >. Acesso em: 17 de outubro de 2019.

\section{DAMÁSIO, António R. O Erro de Descartes: Emoção, Razão e o Cérebro}

Humano. São Paulo: Companhia das Letras, 1994.

DUNKIN' Editorial Staff. Get An Inside Look At Our Next Generation Concept Store In Quincy, MA. 2018. Disponível em: <https://news.dunkindonuts.com/blog/getan-inside-look-at-our-next-generation- concept-store-in-quincy-ma>. Acesso em: 29 de outubro de 2019. 
GABRIEL, Lucas. Os 4 P's do marketing: entenda o conceito do Mix de Marketing. 2018. Disponível em: <https://rockcontent.com/blog/4-ps-do-marketing/>. Acesso em: 09 de setembro de 2019.

GENEZE, Pedro. Experiência do cliente - O principal campo competitivo do futuro. 2018. Disponível em: <https://blog.neoassist.com/experiencia-do-cliente-ofuturo/>. Acesso em: 29 de outubro de 2019.

GPHR. Do espaço sideral para as lojas do Brasil, Starbucks apresenta Galaxy Frappuccino. 2018. Disponível em: <https://www.guiagphr.com.br/noticias/doespaco-sideral-para-as-lojas-do-brasil- starbucks-apresenta-galaxy-frappuccino/> . Acesso em: 17 de outubro de 2019.

HOLANDA, Patrícia Morais de Aquino. Influência do aroma sobre o comportamento do consumidor: um experimento em cafeterias. Fortaleza: Universidade de Fortaleza, 2005. Disponível em: $<$ https://uol.unifor.br/oul/ObraBdtdSiteTrazer.do?method=trazer\&ns=true\&obraCo digo $=82214>$. Acesso em: 09 de setembro de 2019. KAHNEMAN, Daniel. Rápido e Devagar: Duas Formas de Pensar. 2011. Disponível em:

<http://www.ie.ufrj.br/intranet/ie/userintranet/hpp/arquivos/280420161036_Rapid oedev agar_DuasformasdDanielKahneman1.pdf>. Acesso em: 09 de setembro de 2019.

LINDSTROM, Martin. Brandsense: A Marca Multissensorial. São Paulo: Bookman, 2005.

MAESO, Carolina. Entrevista sobre a Starbucks. Entrevista concedida a Bruno Mello. Disponível em:

<https://www.mundodomarketing.com.br/entrevistas/6798/starbucks-conquistaos- brasileiros-sem-propaganda-mas-com-muita-experiencia.html>. Acesso em: 09 de setembro de 2019.

MEIO E MENSAGEM. Copo do Starbucks aparece em episódio de Game of Thrones. 2019. Disponível em:

<https://www.meioemensagem.com.br/home/marketing/2019/05/06/copo-dostarbucks- aparece-em-episodio-de-game-of-thrones.html>. Acesso em: $17 \mathrm{de}$ outubro de 2019.

MORI, Mariana. Fomos conhecer a boutique da Nespresso que tem bar e aulas gratuitas sobre café. 2019. Disponível em:

<https://www.gazetadopovo.com.br/bomgourmet/nespresso-boutique-com-baraulas-gratuitas-cafe/>. Acesso em: 10 de novembro de 2019. 
NEWMAN, Daniel. Want Better Customer Experience? Combine CRM and Customer Feedback. 2018. Disponível em:

<https://www.forbes.com/sites/danielnewman/2018/04/10/want-better-customerexperience-combine-crm-and-customer-feedback/\#6b280b0f3fbb >. Acesso em: 10 de novembro de 2019.

OLIVEIRA, Ana Paula Rezante de. Consumidor brasileiro se interessa mais pelo café gourmet. 2018. Disponível em:

<https://markesalq.com.br/2018/04/11/consumidor-brasileiro-se-interessa-maispelo-cafe-gourmet-por-ana-paula-rezante/> . Acesso em: 29 de outubro de 2019. OLIVEIRA, Priscilla. Casa Pilão: de produto a serviço e franquia. 2015. Disponível em:

<https://www.mundodomarketing.com.br/cases/34629/casa-pilao-de-produto-aservico-e-franquia.html>. Acesso em: 10 de novembro de 2019

OLIVEIRA, Rafael Morais de; BRAGA Nívea Pimenta. Os cinco sentidos no marketing: a importância dos estímulos multissensoriais para despertar a emoção e gerar inclusão social. São Paulo: XVIII Congresso de Ciências da Comunicação na Região Sudeste, 2013. Disponível em:

<http://portalintercom.org.br/anais/sudeste2013/resumos/R38-0514-1.pdf>. Acesso em: 09 de setembro de 2019.

PILÃo. A Casa Pilão é toda sua. 2019. Disponível em:

<https://www.pilao.com.br/casa-pilao>. Acesso em: 10 de novembro de 2019. SALOMÃO, Karin. Dunkin' Donuts muda de nome para brigar com a Starbucks. Exame, 2016. Disponível em: <https://exame.abril.com.br/negocios/dunkindonuts-tira-os-doces-do-nome-para- brigar-com-a-starbucks/>. Acesso em: 09 de setembro de 2019.

SANTOS, Monaliza; ARAÚJO, Priscila; SILVA, Milanda; RIBEIRO, Amanda. A importância dos cinco sentidos para a memória dos idosos: um relato de experiência. 2016. Disponível em:

<http://periodicos.uesc.br/index.php/memorialidades/article/view/1421>. Acesso em: 09 de setembro de 2019.

SCHIMOYAMA, Claudio; ZELA, Douglas Ricardo. Coleção Gestão Empresarial. 2002. Disponível em:

<https://drive.google.com/file/d/0B1eztC3oNlo8X2VFcGFDanY4TTg/view>. Acesso em: 09 de setembro de 2019.

STARBUCKS Corporation. Nosso Legado. 2019. Disponível em:

<https://www.starbucks.com.br/about-us/our-heritage>. Acesso em: 09 de setembro de 2019. 
STARBUCKS Reserve. Visit. 2019. Disponível em:

<https://www.starbucksreserve.com/en-us/visit>. Acesso em: 17 de outubro de 2019.

TYLER, Jessica. We visited Dunkin' Donuts' 'store of the future' in NYC - here's what it was like. 2018. Disponível em: <https://www.businessinsider.com/dunkindonuts-rebranding-stores-photos-details- 2018-8>. Acesso em: 29 de outubro de 2019.

WARNICK, Jennifer. 10 things to know about the Starbucks Reserve Roastery New York. 2018. Disponível em: <https://stories.starbucks.com/stories/2018/10-thingsto-know-about-the-starbucks-nyc-reserve-roastery/>. Acesso em: 17 e outubro de 2019. 